\title{
Relationship between Emotional Regulation Strategies and Self -reported Ego Defense Styles Among Nursing Interns at Alexandria, Main University Hospital
}

\author{
Amal Mohamed Gamal Hussein Shehata, Fatma Hussein Ramadan \\ Assistant Professor, Psychiatric Mental Health Nursing, Faculty of nursing Alexandria University.
}

\begin{abstract}
Internship year represents the first actual contact of the nurse graduates with the real work environment with all its challenges. The transition from student nurse to qualified staff nurse is often filled with overwhelming stress. Many nurse interns reported being distressed and emotionally overwhelmed in dealing with new or traumatic experiences when rotating various critical clinical settings at Alexandria Main University Hospital. The experienced stress is likely to be exacerbated by lack of emotional regulation and adopting immature defenses that cause many forms of defensive behaviors. Consequently, nurses may experience burnout, low satisfaction in professional and social life and resign in the early phases of career. Therefore, this study aimed to identify the relationship between emotional regulation strategies and self-reported ego defense styles among nursing interns at Alexandria Main University Hospital. Subjects of this study included 100 nursing interns in the internship year 2014 -2015. Data was collected by using the following tools: Tool I: Defense Style Questionnaire 40" (DSQ-40), Tool II: Emotion Regulation Questionnaire (ERQ). Data was collected by the researchers after the first month of the beginning of internship year. Results: The finding showed that, mature defense style is positively correlated to cognitive reappraisal of emotional regulation. Whereas, immature defense style was positively correlated to emotional suppression. The only immature defense mechanism that female's interns relied upon more heavily than men was somatization. A significant difference between gender and emotional regulation strategies, female's interns tend to use more cognitive reappraisal, whereas, male tend to use more emotional suppression.
\end{abstract}

Keywords: Emotional Regulation, Ego Defense Styles, Nursing Interns.

\section{Introduction}

Internship year represents the first actual contact of the nurse graduates with the real work environment with all its challenges. The transition from student nurse to qualified staff nurse is often filled with overwhelming stress Research findings suggest that the conflicting demands of being a student and an emerging professional can be particularly distressing (Pearcey and Elliott 2004, Cosimano 2010) ${ }^{1,2}$. Nurse interns directly or indirectly face many stressful situations which play an important role in the acquisition of professional abilities. Despite the negative consequences of stress on psychological growth and quality of patient care, nurse intern's psychological reaction has not been yet studied in nursing research.

Many nurse interns reported being distressed and emotionally overwhelmed in dealing with new or traumatic experiences when rotating various critical clinical settings at Alexandria Main University Hospital. Some of them stated, "When I wanted to examine a patient, I was afraid of doing something that causes harm to the patient. I was hoping for my internship to be just finished as soon as possible". Also, nurse interns feel sympathy with patients and talked about fears and worried that the patient might die; one of nurse interns said, "If any case die, it will be so hard, it really affected me, so I stay away and avoid managing hopeless case as possible". Furthermore, It was observed that during internship year, nurse interns are experiencing bulling behaviors from physicians and senior staff , some of them chose not to report their feelings because of having no authority to set limit or fear of being evaluated negatively by their preceptors , while the others engage in defensive behaviors in the form of acting out and passive aggressive behaviors and some projecting their anger on to others including patients, staff and colleagues.

The experienced stress is likely to be exacerbated by lack of emotional regulation and adopting immature defenses that cause many forms of defensive behaviors (Shiferaw et al. 2015) ${ }^{3}$. Consequently, nurses may experience burnout, low satisfaction in professional and social life and resign in the early phases of career.

Emotion regulation is a key element of most theories of emotion. It refers to a person's ability to understand and accept his or her emotional experience, to engage in healthy strategies to manage uncomfortable emotions when necessary, and to engage in appropriate behavior when distressed. Emotion regulation capacity may enhance the ego functioning that reflected in one's Psychological adaptations. Two commonly used strategies for regulating emotion. The first, cognitive reappraisal, involves changing how one thinks about a 
situation to decrease its emotional impact. The second, emotional suppression, involves inhibiting ongoing emotion-expressive behavior (Lewis 2008, Seiffge- Krenke 2009, Walgast 2011) ${ }^{4,5,6}$.

Psychological adaptations to threats include the various cognitive emotional strategies and even distortions whereby people come to construe a situation in a manner that renders it less threatening to personal worth and wellbeing. Many of these psychological adaptations can be thought of as defensive in nature, insofar as they alter the meaning of the event in a way that shields people from the conclusion that their beliefs or actions were misguided (Sherman \& Cohen 2006) ${ }^{7}$.

As a reaction to stress, the prevalence of ego defense mechanisms has been employed. Defense mechanisms in DSM-IV have been proposed to protect as an automatic mental process of the individual against anxiety and internal and external factors that are causing stress (Kronström 2011) ${ }^{\mathbf{8}}$. The concept of defense mechanisms was defined for the first time by Sigmund Freud as unconscious resources used by the ego to reduce the conflict between the id and the superego. Colman (2009) ${ }^{9}$ who claimed that defense mechanism is a pattern of feeling, thought, or behavior arising in response to a perception of psychic danger, enabling a person to avoid conscious awareness or conflicts or anxiety-arousing ideas or wishes. As the level of anxiety increases, the strength of the ego is tested, and energy is mobilized to confront the threat (Larsen etal.2010) ${ }^{\mathbf{1 0}}$. Although Sigmund Freud initially described defense mechanisms as pathological, Anna Freud viewed them as part of normal development, except when used too frequently or in age-inappropriate ways (Cramer 2005) ${ }^{11}$.

Several researchers have viewed defense mechanisms as existing on a continuum and can be grouped as mature, immature, and neurotic, referring to the adaptiveness of each defense. Mature ego defenses are the most adaptive and include humor, sublimation, and suppression. Immature ego defenses include more childish mechanisms such as regression, passive aggression, and acting out. Neurotic ego defenses are the least adaptive, including mechanisms like displacement, repression, and isolation, and are generally seen in more pathological populations 'Vaillant,1992, Steiner et al. 2001, Cour 2002) ${ }^{12,13,14}$.

Vaillant (1992) ${ }^{12}$ identified the maturity of defenses as a predictor of the ability to form and maintain stable interpersonal relationships. Utilizing mature defense style is an important skill required for optimum emotional regulation and performance (Waqas et al. 2015) ${ }^{15}$. Malone et al. (2013) ${ }^{16}$ showed that mature defenses allow better modulation of distress while maintaining engagement with reality and greater levels of success in work and relationships and lower levels of psychopathology; neurotic defenses are less adaptive but are found across all levels of life functioning; whereas immature defenses are associated with difficulty regulating, expressing, and understanding emotional experiences.

Despite the assessment of defensive styles in research, neither appears to have a structure that accurately describes the defensive styles or factors of separate samples of men and women. Such failure to adequately reflect gender-specific defensive patterns is particularly glaring given the prevalence of research strongly suggesting that men and women differ in their defense use (Mahalik et al., 1998; Watson \& Sinha, 1998, Cramer, 2009; Petraglia et al., 2009, Drapeau et al. 2011) ${ }^{17,18,19,20,21}$.

Psychological defense mechanisms represent a crucial component of individuals' capacity to maintain emotional homeostasis. Without them the conscious mind would be much more vulnerable to negatively charged emotional input (Luhmann 2014) ${ }^{22}$. Body of research indicates that working in the helping professions is emotionally demanding (Eren 2016) ${ }^{23}$. The findings of an international study of intern nurses conducted by Aitken et al. (2012) ${ }^{24}$ reported that $42 \%$ of the subjects described themselves as "burned out". Being aware to emotional experiences in a way that is emotions (Blaya et al., 2006) ${ }^{25}$.

Raising awareness among nurse interns and staff involved in nurse education and clinical practice during internship year, with the relationship between ego defense styles and emotional regulation could prompt the development of strategies to potentially prevent or at least reduce stress in the work environment and hopefully identify areas where contingency plans need to be put in place to support nurse interns in the clinical environment. Therefore, the current study was intended to identify the relationship between defense mechanism styles and emotional regulation strategies among nursing interns.

\section{Aim of the study:}

This study aimed to identify the relationship between emotional regulation strategies and self -reported ego defense styles among nursing interns at Alexandria Main University Hospital.

\section{Research questions:}

- What is the relation between emotional regulation strategies and self-reported ego defense styles among nurse interns at Alexandria Main University Hospital?

- To what extent are there differences in using emotional regulation strategies and self-reported ego defense styles between male and female nurse interns at Alexandria Main University Hospital? 
Materials

\section{Materials \& Method}

Study design: -

This study follows a descriptive correlational design.

Setting:

The study was conducted at Alexandria Main University Hospital at the departments in which student interns are enrolled. These departments include urology department, neurology intensive care unit, burn intensive care, unit I and unit III, triage care unit and anesthesia intensive care unit.

\section{Subjects:}

Subjects of this study included 100 nursing interns in the internship year $2014-2015$. They were selected by using EPI Info 7 program applying the following information:

Population size $=180$ Expected frequency $=50 \%$

Acceptable error $=5 \%$ Confidence coefficient $=95 \%$

Sample size $=100$ student interns.

Subjects were selected randomly.

Tools of the study:

Data was collected by using the following tools:

\section{Tool I: Defense Style Questionnaire 40”, (DSQ-40):}

Defense Style Questionnaire 40 was developed by Andrews et al (1993) ${ }^{\mathbf{2 6}}$, the scale is selfadministered and consists of 40 short statements, the primary aim of the DSQ-40 is to measure and differentiate between impaired and unimpaired defenses. It is a measure of 20 defense mechanisms consistent with those in the DSM-IV-TR (American Psychiatric Association, 2003). These defense styles are grouped as mature (sublimation, suppression, anticipation, altruism, and humor), immature (projection, passive aggression, acting out, fantasy, hypochondriasis, and dissociation), and neurotic (displacement, repression, isolation, and reaction formation). Items are rated on a Likert scale ranging from 1 ("strongly disagree") to 9 ("strongly agree") based on personal agreement with the statement. Defenses are scored by taking a mean score of the representative items. Cronbach's alphas of $0.65,0.63$ and 0.82 were reported for the three defense styles of mature, neurotic and immature respectively.

\section{Tool II - Emotion Regulation Questionnaire (ERQ):}

Emotion Regulation Questionnaire was developed by Gross \& John (2003) ${ }^{\mathbf{2 7}}$. It is a 10-item scale designed to assess respondents' tendency to regulate their emotions in the habitual use of two emotion regulation strategies: cognitive reappraisal and expressive suppression. Respondents answer each item on a 7point Likert-type scale ranging from 1 (strongly disagree) to 7 (strongly agree). It is scored by taking a mean score of the representative items. Internal consistency obtained by Cronbach's alpha coefficient for the factors of cognitive reappraisal and emotional suppression were 0.73 and 0.75 , respectively.

In addition, socio-demographic data was obtained by the researchers to elicit data about the general sociodemographic characteristics of the student intern such as age, sex, place of residence and their cumulative GPA.

\section{Preparation of the study tools:}

\section{Method}

- Written approval was obtained from the faculty dean and the vice dean for student affairs to send it to the manager of the Main University Hospital to collect the necessary data.

- $\quad$ Tools I and II were translated into Arabic; and tested for content validity by a jury of 5 experts in the field of psychiatric nursing and mental health.

- $\quad$ Tool I and tool II were tested for its reliability using Cronbach's alpha coefficient on 20 nursing interns. They were excluded from the study subjects.

\section{Pilot study:}

A pilot study was carried out on 10 nursing interns who were selected randomly to test tool clarity, feasibility, time needed to fill and understanding of the study tools. The results of pilot study revealed that the tools were clear and applicable. These subjects were excluded from the actual study subjects.

\section{Actual Study:}

- Data was collected by the researchers after the first month of the beginning of internship year. The questionnaire was hand delivered to each study subject at the identified study setting.

- The data was collected for a period of one month in December 2014. The researchers met the student interns individually in the break during morning shift to explain the purpose of the study and then provide instructions regarding answering the study tools. 
Relationship between Emotional Regulation Strategies and Self-reported Ego Defense Styles ..

\section{Ethical considerations:}

Written informed consent was obtained before attaining the participants' voluntary involvement in tool completion. Nursing interns have to sign an informed consent which included the purpose of the study and their rights to participate or withdraw at any time without any negative consequences in their internship grading. Upon written agreement, the nursing graduates were given the questionnaire in the presence of the researcher to clarify any vague questions. Anonymity and privacy were assured by telling the interns to avoid putting their names on the questionnaire.

\section{Statistical analysis:}

Data was fed, coded, edited and analyzed using the PC with Statistical Packages for Social Science (SPSS 22) and Windows Version 7.0. The selected level of significance was at $p \leq 0.05$. Descriptive statistics were done using numbers, percentage, arithmetic mean and standard deviation. Pearson statistical test was used to quantify the strength of the association between the study variables. Also, Student t-test was used to determine the difference between two groups.

\section{Results}

Table (1): reveals the Socio-demographic characteristics of the studied interns. The age of the studied interns ranged from 21 to 24 years, with a mean age $22.50 \pm 1.24$ years. More than two thirds of them $(69 \%)$ were females. Almost two thirds (64\%) lived at rural areas. Regarding their academic achievement, $23 \%$ of them obtained $\mathrm{C}+, 22 \%$ obtained $\mathrm{C}$ - and $21 \%$ obtained B.

Table (2): shows the distribution of the studied nurse interns according to their total percent mean score of ego defense mechanisms. The highest percent mean score was for mature ego defense mechanisms (59.47 \pm 9.54), Anticipation has the highest mean score among nurse interns among the mature defenses. Whereas immature defense mechanism had the lowest percent score among the studied interns $(49.31 \pm 12.18)$, the highest mean score among this group was for rationalization and somatization $(11.40 \pm 3.42 \& 11.25 \pm 4.07$ respectively). As regard, neurotic ego defense mechanisms, the total percent mean score was $55.84 \pm 14.95$, Pseudo-altruism has the highest mean score among the studied interns in neurotic defenses (12.52 \pm 3.36$)$.

Table (3): shows the distribution of the studied nurse interns according to their mean score of emotional regulation strategies. It was noted that cognitive reappraisal strategy had a higher mean score $(30.23 \pm$ 7.42) than emotional suppression strategy $(17.17 \pm 5.58)$ among nurse interns.

Table (4): presents the relationship between ego defense mechanisms and emotional regulation strategies among the studied nurse interns, this table shows that total mature defense mechanism was significantly correlated with cognitive reappraisal emotional regulation strategy $(\mathrm{r}=0.355, \mathrm{p}=<0.001)$, suppression and sublimation as mature defenses were significantly correlated with cognitive reappraisal emotional regulation strategy $(r=0.240, p=0.016 \& r=0.346, p=<0.001$ respectively). Furthermore, neurotic defense mechanisms were significantly correlated with cognitive reappraisal $(r=0.365, p=<0.001)$, pseudoaltruism and reaction formation were also positively correlated with cognitive reappraisal $(\mathrm{r}=0.270, \mathrm{p}=0.007 \&$ $\mathrm{r}=0.347, \mathrm{p}=<0.001$ respectively). Whereas, the total immature defense mechanisms were positively correlated with emotional suppression emotional regulation strategy $(\mathrm{r}=0.322, \mathrm{p}=<0.001)$.

Table (5): reveals the relationship between ego defense mechanisms, emotional regulation strategies and the studied interns' gender, it was noted that male interns had higher mature mean score $(64.67 \pm 12.75)$ than female interns $(57.13 \pm 15.30)$ with significant difference between them $(\mathrm{t}=.2 .39 \mathrm{p}=0.019 *)$. Whereas, female interns had higher neurotic mean score $(56.73 \pm 14.96)$ than male interns $(53.88 \pm 14.98)$ with no significant difference $(\mathrm{t}=0.879, \mathrm{p}=0.381)$. The total mean score of immature defenses among male interns $(51.31 \pm 11.76)$ was higher than females $(48.41 \pm 12.34)$ with no significant difference was found $(\mathrm{t}=1.103$, $\mathrm{p}=0.273$ ). It also observed that passive aggressive defense mechanism was significantly different between male and female interns $(\mathrm{t}=2.286, \mathrm{p}=0.024)$, male interns had higher mean score than female interns in passive aggressive defense mechanism(47.98 $\pm 20.63 \& 37.23 \pm 22.24$ respectively).In relation to gender difference in emotional regulation, a significant difference was found between male and female interns in relation to emotional suppression $\left(\mathrm{t}=4.029^{*}, \mathrm{p}=<0.001^{*}\right)$, male interns had higher mean score $(67.88 \pm 22.83)$ than female interns $(49.03 \pm 21.08)$. In addition, denial, isolation and acting out defenses were higher in male interns than in females. While somatization defense mechanism was higher in females as compared to males. 


\section{Discussion}

Defense style and emotional regulation are crucial to healthy mental functioning, and that disturbances in them play an important role in psychopathology. Hence, the current study would shed light on individual differences in defense use in relation to emotional regulation among nursing interns. According to the results of the present study, mature defense style has positive and significant correlation with cognitive reappraisal of emotional regulation. An explanation to this results, as Coping is a situational based, Successful coping with a situation seems to require the thinking ability to do when the problems are within his/ or her control to cope and function as a self-reliant through using mature defenses and cognitive reappraisal.

In addition, Suppression and sublimation were significantly and positively correlated with cognitive reappraisal. Consistent with these results, Waqas et al. (2015) ${ }^{15}$ reported that the use of mature defenses such as sublimation enhances pleasure and feelings of control and suppression helps in integrating conflicting emotions and thoughts. This result was in concordance with a study in Iran found that nurses who use mature defense style in stress and anxiety situations have better psychological well-being than nurses who use of neurotic and immature defense styles (Ghadimianfar\& Dadkhah 2015) ${ }^{28}$. This method of mature coping can decrease emotional distress and implies a greater ability to accept the unpleasant aspects of clinical situations with consequent better self- management and promote professional nursing practice.

Furthermore, Viallant (2000) ${ }^{29}$ found that mature defenses are correlated with better adaptability and compatibility in life on some college students. Moreover, Sepidehdam et al. (2012) ${ }^{30}$ showed that the more mature mechanisms people have the less emotionally fatigued they feel. It was also found a negative significant relation between mature defenses and the symptoms of depression, fatigue and the poor life quality. This means that the use of mature defenses by nurse interns will overcome their problems through adaptive coping and renders them not vulnerable to various forms of psychological distress.

In the current study, immature defenses style was positively and significantly correlated with suppressive emotional regulation. This may be related to the fact that immature defenses style are nonadaptive and inefficient confrontation methods. According to the present finding, rationalization and somatization had the highest mean scores among nursing interns. This finding may be attributed to the fact that immature defenses style was adopted by individuals to prevent them from the awareness of their own unacceptable thoughts, impulses or wishes resulting into anxiety. These defense mechanisms regulate the individual's inner psychological state through self-deception and emotional suppression. Maintaining immature defenses, requires psychological energy that limits emotional flexibility and true self-awareness. In this regard, Malone et.al. (2013) ${ }^{31}$ showed in a pilot study that emotional disorder is positively correlated with immature defenses and negatively correlated with mature defense styles and not correlated with neurotic defense styles. Immature defense styles are associated with poor adjustment as an adult, poor friendship patterns, higher incidence of mental illness, greater number of sick leave days taken and poorer health generally, personality disorders, depression.

Consistent with the current results, a study done by Javaheri et al. (2011) ${ }^{32}$ found that immature defenses have a positive correlation with anger expression and its subscales such as verbal and physical emergence of anger, angry mood and reactions. Furthermore, those who use immature and neurotic defense mechanisms avoid experiencing their feelings which does not mean eliminating it, but the feeling is being suppressed and projects through behaviors which are sometimes out of control Ghadimianfar\& Dadkhah $2015)^{28}$.

As regard gender differences in defensive style, the results of the present study showed that, men are significantly more likely to adopt mature defenses than females, this finding may be related to the gender differences in behavior between males and females. Males often seek straight forward solutions to problems, while females have emotional approach to problems. Zeigler-Hill and Pratt, (2007) ${ }^{\mathbf{3 3}}$ found that the use of mature defenses is associated with dominance among men but with nurturance among women. Studies have shown that men and women differ in their use of defense mechanisms (e.g. Cramer, 2009, Watson and Sinha, 1998) ${ }^{19,18}$ However, Drapeau et al (2011) $)^{21}$ found that There was no statistically significant difference in the prevalence of mature defense mechanisms amongst the males than females. 
Gender differences have been found in the use of defenses. It was found that men use internalizing defenses and projection more than females, and women use externalizing defenses, denial, and reaction formation more than males (Cramer, 2005, 2009) $)^{34,19}$. In addition, the current study showed that, the mean score of neurotic mechanisms was higher in females than males. Most studies using the DSQ have found no gender differences. In study using adolescent samples, females were found to score higher on neurotic defenses than males (Malone 2013) ${ }^{\mathbf{3 1}}$. First, females constituted more than two third of the study subjects. These findings attributed to the fact that females by nature are highly emotional affected than males. Additionally, using neurotic mechanisms among females to shield them from experiencing unacceptable thoughts or feelings in the work setting or stressful shift work as a new experience. this may result in a distortion of some aspect of reality.

Also, it was noted that males scored high immature defenses than females. In agreement with this results. Luxen (2005) ${ }^{35}$ evealed that males reported greater use of immature defense mechanisms: isolation, dissociation, devaluation, denial, and passive aggression. The only immature defense mechanism that women relied upon more heavily than men was somatization, that observed in the current study. This can be explained by the fact that male and female may differ in promoting or overcoming their feelings or in their using emotional regulation strategies. therefore, Nurse interns who are use somatization may withdraw or escape from situations as discomfort, fatigue, burnout and/or fears which adopting to use immature defenses.

In addition, the present results showed significant difference between gender and emotional regulation strategies, female's interns tend to use more cognitive reappraisal, whereas, male tend to use more emotional suppression. This finding may be attributed to the common belief is that women are more in touch with their feelings than men are - that they react more emotionally and are better able to read emotions in others. women show greater emotional expression than men, they experience emotions more intensely; and they display more frequent expressions of both positive and negative emotions. In contrast to men, women also report more comfort in expressing emotions (Martha et al 1997) ${ }^{36}$. Researchers have suggested three possible explanations for these differences. One explanation is the different ways men and women have been socialized. Men are taught to be tough and brave. Showing emotion is inconsistent with this image. Women, in contrast, are socialized to be nurturing. This may account for the perception that women are generally warmer than men. For instance, women are expected to express more positive emotions on the job (shown by smiling) than men, and they do. A second explanation is that women may have more innate ability to read others and present their emotions than do men. Third, women may have a greater need for social approval and, so, a higher propensity to show positive emotions, such as happiness (Drapeau et al. 2011, Petraglia et al 2009) 21,20

\section{Conclusion}

It can be concluded from the present study that defense styles may be at least distinguishable with regard to nurse interns' emotional regulation strategies. The finding showed that, mature defense style is positively correlated to cognitive reappraisal of emotional regulation. Whereas, immature defense style was positively correlated to emotional suppression. Therefore, emotional regulation might be improved through utilizing adapted or mature defense styles in order to prepare nurse interns to fulfill their experiences more effectively.

In the light of the results of the present study, the following recommendations are suggested:

- Faculty of nursing should apply mental health promotion program with nurse interns at the beginning of internship year to support them to use adapted defenses and eliminate the maladaptive one, and to regulate unwanted feeling objectively.

- Increase nurse intern's awareness about psychological defense mechanisms which can lead to decrease of internal conflict which in turn can lead to increased integrative function of inner energies.

- Defense mechanisms have been investigated in relation to stress and burnout among nurse interns.

- Use organizational behavior brochures and include fruitful discussion on nurse interns defense mechanisms correction in them.

- Use defense mechanisms test to provide mental occupational profile.

\section{Limitation of the study:}

One limitation of the present study was its reliance on self-report measures of defense style. In this respect, Davidson and MacGregor (1998) postulated that defense mechanisms tend to operate outside of conscious awareness which would seemingly preclude the possibility of useful self-reports. 


\section{Results}

Table (1): Socio-demographic characteristics among the studied nurse interns

\begin{tabular}{|l|c|c|}
\hline & $\begin{array}{c}\text { No. } \\
(\mathbf{n = 1 0 0})\end{array}$ & $\%$ \\
\hline Age (21-24 years) & \multicolumn{2}{|c|}{} \\
$\leq 22$ & 65 & 65.0 \\
$>22$ & 35 & 35.0 \\
\hline Mean SD. & \multicolumn{2}{|c|}{$22.50 \pm 1.24$} \\
\hline Gender & 31 & 31.0 \\
Male & 69 & 69.0 \\
Female & & \\
\hline Residence & 36 & 36.0 \\
Urban & 64 & 64.0 \\
Rural & & \\
\hline Academic achievement & & 22.0 \\
Grade Point Average(GPA) & 22 & 11.0 \\
C - & 11 & 23.0 \\
C & 23 & 13.0 \\
C + & 13 & 21.0 \\
B - & 21 & 8.0 \\
B & 8 & 2.0 \\
B + & 2 & \\
A & \multicolumn{2}{|c|}{} \\
\hline
\end{tabular}

Table (2): Self-reported ego defense styles among the studied nurse interns ( $\mathrm{n}=100)$

\begin{tabular}{||l|c|c|}
\hline \multicolumn{1}{|c|}{ Ego defense mechanisms } & Mean (SD) & Percent score \\
\hline Mature & $\mathbf{4 6 . 0 6} \pm \mathbf{9 . 5 4}$ & $\mathbf{5 9 . 4 7} \pm \mathbf{9 . 5 4}$ \\
Suppression & $11.56 \pm 3.96$ & $59.75 \pm 24.75$ \\
Sublimation & $10.90 \pm 3.77$ & $55.63 \pm 23.56$ \\
Humor & $11.45 \pm 3.83$ & $59.06 \pm 23.94$ \\
Anticipation & $12.15 \pm 3.58$ & $63.44 \pm 22.39$ \\
\hline Neurotic & $\mathbf{4 3 . 7 4} \pm \mathbf{9 . 5 6}$ & $\mathbf{5 5 . 8 4} \pm \mathbf{1 4 . 9 5}$ \\
Pseudo altruism & $12.52 \pm 3.36$ & $65.75 \pm 21.03$ \\
Undoing & $11.29 \pm 3.96$ & $58.06 \pm 24.75$ \\
Idealization & $9.97 \pm 4.11$ & $49.81 \pm 25.69$ \\
Reaction formation & $9.96 \pm 4.22$ & $49.75 \pm 26.37$ \\
\hline Immature & $\mathbf{1 1 8 . 6 2} \pm \mathbf{2 3 . 3 7}$ & $\mathbf{4 9 . 3 1} \pm \mathbf{1 2 . 1 8}$ \\
Projection & $8.68 \pm 3.87$ & $41.75 \pm 24.18$ \\
Passive aggression & $8.49 \pm 3.55$ & $40.56 \pm 22.22$ \\
Denial & $8.64 \pm 4.05$ & $41.50 \pm 25.34$ \\
Dissociation & $8.93 \pm 3.86$ & $43.31 \pm 24.12$ \\
Acting out & $10.44 \pm 3.98$ & $52.75 \pm 24.88$ \\
Devaluation & $10.93 \pm 3.46$ & $55.81 \pm 21.62$ \\
Displacement & $9.33 \pm 4.05$ & $45.81 \pm 25.31$ \\
Splitting & $9.67 \pm 4.25$ & $47.94 \pm 26.59$ \\
Isolation & $9.95 \pm 4.12$ & $49.69 \pm 25.75$ \\
Rationalization & $11.40 \pm 3.42$ & $58.75 \pm 21.39$ \\
Autistic Fantasy & $10.91 \pm 4.79$ & $55.69 \pm 29.94$ \\
Somatization & $11.25 \pm 4.07$ & $58.37 \pm 25.72$ \\
\hline
\end{tabular}

Table (3): Emotional regulation strategies among the studied nurse interns $(n=100)$

\begin{tabular}{||l|c|c||}
\hline \multicolumn{1}{|c|}{ Emotional regulation strategies } & Mean $($ SD $)$ & Percent score \\
\hline & $30.23 \pm 7.42$ & $67.31 \pm 20.62$ \\
Cognitive reappraisal & $17.17 \pm 5.58$ & $54.87 \pm 23.23$ \\
Emotional suppression & $47.70 \pm 10.45$ & $62.33 \pm 17.41$ \\
Total mean score & & \\
\hline
\end{tabular}


Relationship between Emotional Regulation Strategies and Self-reported Ego Defense Styles ..

Table (4): Relationship between self-reported ego defense styles and emotional regulation strategies among the studied nurse interns $(\mathrm{n}=100)$

\begin{tabular}{||l|c|c|c|c||}
\hline \multirow{2}{*}{\multicolumn{1}{|c|}{ Ego defense mechanisms }} & \multicolumn{3}{|c|}{ Emotional regulation strategies } \\
\cline { 2 - 5 } & \multicolumn{2}{|c|}{ Cognitive Reappraisal } & \multicolumn{2}{c|}{ Emotional Suppression } \\
\cline { 2 - 5 } & $\mathbf{R}$ & $\mathbf{P}$ & $\mathbf{R}$ & $\mathbf{P}$ \\
\hline Mature & $\mathbf{0 . 3 5 5}$ & $<\mathbf{0 . 0 0 1}$ * $^{*}$ & $\mathbf{0 . 1 4 8}$ & $\mathbf{0 . 2 7 8}$ \\
Suppression & 0.240 & $0.016^{*}$ & -0.115 & 0.254 \\
Sublimation & 0.346 & $<0.001^{*}$ & 0.157 & 0.119 \\
Humor & 0.198 & 0.049 & -0.124 & 0.218 \\
Anticipation & 0.106 & 0.295 & 0.098 & 0.330 \\
\hline Neurotic & $\mathbf{0 . 3 6 5}$ & $<\mathbf{0 . 0 0 1}{ }^{*}$ & $\mathbf{- 0 . 0 4 9}$ & $\mathbf{0 . 6 2 7}$ \\
Pseudo- altruism & 0.270 & $0.007^{*}$ & 0.162 & 0.107 \\
Undoing & 0.105 & 0.299 & -0.107 & 0.287 \\
Idealization & 0.170 & 0.090 & -0.086 & 0.394 \\
Reaction formation & 0.347 & $<0.001^{*}$ & -0.056 & 0.580 \\
\hline Immature & $\mathbf{0 . 1 1 5}$ & $\mathbf{0 . 2 5 3}$ & $\mathbf{0 . 3 2 2}$ & $<\mathbf{0 0 0 1}$ \\
Projection & 0.105 & 0.297 & 0.011 & 0.917 \\
Passive aggression & -0.066 & 0.517 & 0.148 & 0.141 \\
Denial & -0.036 & 0.721 & 0.049 & 0.630 \\
Dissociation & 0.050 & 0.619 & 0.036 & 0.720 \\
Acting out & 0.070 & 0.489 & 0.109 & 0.278 \\
Devaluation & -0.020 & 0.842 & 0.069 & 0.494 \\
Displacement & -0.022 & 0.828 & 0.103 & 0.306 \\
Splitting & 0.172 & 0.087 & 0.164 & 0.103 \\
Isolation & 0.045 & 0.657 & 0.007 & 0.945 \\
Rationalization & -0.035 & 0.726 & 0.020 & 0.846 \\
Autistic Fantasy & 0.133 & 0.188 & 0.016 & 0.877 \\
Somatization & 0.132 & 0.190 & -0.047 & 0.642 \\
\hline
\end{tabular}

r: Pearson coefficient

*: Statistically significant at $\mathrm{p} \leq 0.05$

Table (5): Emotional regulation strategies and self-reported ego defense styles among male and female nurse interns

\begin{tabular}{|c|c|c|c|c|}
\hline \multirow[b]{2}{*}{ Ego defense mechanisms } & \multicolumn{2}{|c|}{ Sex } & \multirow[b]{2}{*}{$\mathbf{T}$} & \multirow[b]{2}{*}{$\mathbf{P}$} \\
\hline & $\begin{array}{c}\text { Male } \\
(n=31)\end{array}$ & $\begin{array}{c}\text { Female } \\
(n=69)\end{array}$ & & \\
\hline Mature & $64.67 \pm 12.75$ & $57.13 \pm 15.30$ & $2.392^{*}$ & $0.019^{*}$ \\
\hline Suppression & $66.33 \pm 20.01$ & $56.79 \pm 26.21$ & 1.955 & 0.050 \\
\hline Sublimation & $57.86 \pm 17.23$ & $54.62 \pm 25.96$ & 0.737 & 0.463 \\
\hline Humor & $64.52 \pm 22.50$ & $56.61 \pm 24.32$ & 1.537 & 0.127 \\
\hline Anticipation & $69.96 \pm 20.57$ & $60.51 \pm 22.70$ & 1.981 & 0.050 \\
\hline Neurotic & $53.88 \pm 14.98$ & $56.73 \pm 14.96$ & 0.879 & 0.381 \\
\hline Pseudo altruism & $67.14 \pm 21.65$ & $65.13 \pm 20.88$ & 0.440 & 0.661 \\
\hline Undoing & $55.44 \pm 24.99$ & $59.24 \pm 24.74$ & 0.707 & 0.481 \\
\hline Idealization & $48.59 \pm 27.32$ & $50.36 \pm 25.11$ & 0.318 & 0.751 \\
\hline Reaction formation & $44.35 \pm 25.38$ & $52.17 \pm 26.62$ & 1.378 & 0.171 \\
\hline Immature & $51.31 \pm 11.76$ & $48.41 \pm 12.34$ & 1.103 & 0.273 \\
\hline Projection & $37.10 \pm 22.18$ & $34.84 \pm 24.90$ & 1.294 & 0.199 \\
\hline Passive aggression & $47.98 \pm 20.63$ & $37.23 \pm 22.24$ & $2.286^{*}$ & $0.024^{*}$ \\
\hline Denial & $48.39 \pm 22.93$ & $38.41 \pm 25.91$ & 1.844 & 0.068 \\
\hline Dissociation & $44.96 \pm 23.69$ & $42.57 \pm 24.45$ & 0.456 & 0.649 \\
\hline Acting out & $57.46 \pm 20.88$ & $50.63 \pm 26.35$ & 1.390 & 0.169 \\
\hline Devaluation & $59.07 \pm 21.76$ & $54.35 \pm 21.55$ & 1.011 & 0.315 \\
\hline Displacement & $47.58 \pm 23.53$ & $45.02 \pm 26.20$ & 0.466 & 0.642 \\
\hline Splitting & $49.40 \pm 19.59$ & $47.28 \pm 29.30$ & 0.424 & 0.673 \\
\hline Isolation & $54.44 \pm 19.04$ & $47.55 \pm 28.12$ & 1.430 & 0.156 \\
\hline Rationalization & $60.28 \pm 19.73$ & $58.06 \pm 22.20$ & 0.478 & 0.634 \\
\hline Autistic Fantasy & $56.85 \pm 28.43$ & $55.16 \pm 30.79$ & 0.260 & 0.795 \\
\hline Somatization & $52.22 \pm 28.39$ & $61.14 \pm 24.13$ & 1.618 & 0.109 \\
\hline Emotional regulation strategies & & & & \\
\hline Reappraisal & $67.83 \pm 18.14$ & $67.07 \pm 21.76$ & 0.170 & 0.865 \\
\hline Suppression & $67.88 \pm 22.83$ & $49.03 \pm 21.08$ & $4.029^{*}$ & $<0.001^{*}$ \\
\hline
\end{tabular}

t: Student t-test, *: Statistically significant at $\mathrm{p} \leq 0.05$ 


\section{References}

[1]. Pearcey PA ${ }^{1}$, Elliott BE. Student impressions of clinical nursing. Nurse Educ Today. 2004 Jul;24(5):382-7.

[2]. Cosimano A. The Experience of New Nursing Graduates on Labor and Delivery Units: A Phenomenological Approach. in partial fulfillment of the requirement for the degree of Doctor in Education 2010 page.21-24 Available at: http://www.csm.edu/sites/default/files/Cosimano.pdf.

[3]. Shiferaw H, Anand N, Nemera, N. Stress and coping strategies among genetic B.Sc. nursing students of jimma university, south west Ethiopia International Journal of Recent Advances in Multidisciplinary Research 2015;2(7):511

[4]. Lewis M, Haviland-Jones J, Barrrett L. Handbook of Emotions.3rd edition .Guilford Press. New York, London 2008.

[5]. Seiffge-Krenke, I., Aunola, K., \& Nurmi, J.-E. Changes in stress perception and coping during adolescence: The role of situational and personal factors. Child Development,2009; 80:259-279.

[6]. Wolgast M, Lundh I, Viborg G.Anonymous. American Psychiatric Association Committee on Nomenclature and Statistics. Diagnostic and statistical manual of mental disorders. 4th ed. Washington, DC: American Psychiatric Press 1994. Kaplan-andSadocks-Study-Guide Available: https://www.scribd.com/document/321151792.

[7]. Sherman, D. K., \& Cohen, G. L. The psychology of self-defense: Self-affirmation theory. In M. P. Zanna (Ed.) Advances in Experimental Social Psychology2006, Vol. 38:183-242.

[8]. Kraustrom K. personality and depression. Department of Psychiatry,University of Turku, Finland Graduate School of Psychiatry, Finland (2011).

[9]. Colman, A. M. A Dictionary of Psychology. 3rd edn. Oxford University Press, Oxford (2009).

[10]. Larsen, A., Bøggild, H., Mortensen, J., Foldager, L., Hansen, J., Christensen, A., \& ... Munk-Jørgensen, P. Psychopathology, defense mechanisms, and the psychosocial work environment. International Journal of Social Psychiatry(2010); 56(6): 563-577. doi:10.1177/0020764008099555.

[11]. Cramer, P., \& Tracy, A. The pathway from child personality to adult adjustment: The road is not straight. Journal of Research in Personality 2005, 39, $369-39$.

[12]. Vaillant, GE. Ego mechanisms of defense: A guide for clinicians and researchers. Washington DC: American Psychiatric Association 1992.

[13]. Steiner H., Araujo K. B. Koopman C. The Response Evaluation Measure (REM- 71): A new instrument for the measurement of defenses in adults and adolescents. American Journal of Psychiatry 2001, 158, 467-473.

[14]. Cour P. Psychological Defenses of Danish Medical Students Journal of Nervous \& Mental Disease 2002 190(1):22-6 .

[15]. Waqas A, Rehman A, MalikA, Muhammad U, Khan S Mahmood N. Association of Ego Defense Mechanisms with Academic Performance, Anxiety and Depression in Medical Students: A Mixed Methods Study 2015. https://www.researchgate.net/publication/282325178.

[16]. Malone J, Cohen S, Liu S, Vaillant G, Waldinger R.Adaptive midlife defense mechanisms and late-life health Personality and Individual differences2013/256541723_Adaptive_midlife_defense_mechanisms and late-life health.vailable at: https://www.researchgate.net/publication.

[17]. Mahalik J, Cournoyer R, DeFranc W, Cherry M, Napolitano J. Men's gender role conflict and use of psychological defenses. Journal of Counseling Psychology 1998; 45: 247-55.

[18]. Watson C, Sinha B. Gender, age, and cultural differences in the Defense Style Questionnaire-40. Journal of Clinical Psychology 1998; Volume 54 (1):67-75.

[19]. Cramer, P. Seven Pillars of defense mechanism theory. (2009) Retrieved from http://www.psychomedia.it/rapaport-klein.2015

[20]. Petraglia, J., Thygesen, K. L., Lecours, S., \& Drapeau, M. Gender differences in self-reported defense mechanisms: a study using the new defense style questionnaire - 60. American Journal of Psychotherapy, 2009; 63(1), 87-99.

[21]. Drapeau M, Thompson K, PetragliaJ, Thygesen K, Lecours S. Defense Mechanisms and Gender: An Examination of Two Models of Defensive Functioning Derived from the Defense Style Questionnaire. International Journal of Psychology and Psychological Therapy 2011; 11 (1): pp. 149-55.

[22]. Luhmann, M., Hofmann, W., Eid, M., \& Lucas, R. E. Subjective well-being and adaptation to life events: A meta-analysis. Journal of Personality and Social Psychology, 2012; 102(3), 592-615.

[23]. Eren N, Sahin S. An evaluation of the difficulties and attitudes mental health professionals experience with people with personality disorders. Journal of mental health nursing.2016; Volume23,1(2): 22-36.

[24]. Atiken L, Clarke S, Sloane D, Lake E, Cheney T. Effects of hospital care environment on patient mortality and nurse outcomes. Journal of Nursing Administration 2008; 38(5): 223-9.

[25]. Blaya C. Dornelles M, Blaya R. Kipper L, Heldt E, Isolan L. Bond M, Manfro G. Does defense mechanism vary according to the psychiatric disorder? Brazil Journal of Psychiatry 2006; 28 (3):1-5.

[26]. Andrews G, Singh M, Bond M. The Defense Style Questionnaire. Journal of Nervous and Mental Disease 1993, 181, $246-256$.

[27]. Gross, J. John, O. Individual differences in two emotion regulation processes: Implications for affect, relationships, and wellbeing. Journal of Personality and Social Psychology2003, 85, 348-362.

[28]. Ghadimianfar M, Dadkhah A. Prediction of Rehabilitation Nurses' Psychological Well-Being Through Personality Traits and Defense Mechanisms Iranian Rehabilitation Journal 2015, Vol. 13, Issue 4 :40-45.

[29]. Vaillant GE. Adaptive mental mechanisms: their role in a positive psychology. Am Psychologist. 2000;55(1):89-98.

[30]. Sepidehdam F, Karimi Y, and Besharat M. The Relation between Defense Mechanisms and Job Burnout among Iran AIR Staff. International Journal of Social Science and Humanity 2012; 2(3) :1-5.

[31]. Malone, J. C., Cohen, S., Liu, S. R., Vaillant, G. E., \& Waldinger, R. J. Adaptive midlife defense mechanisms and late-life health. Personality and Individual Differences, 2013; 55(2), 85-89.

[32]. Javaheri A, Ghanbari S, Zarandi AR. Relationship between defense mechanisms with experience and express of anger in female university student's J Appl Psychol.2011;5(18):97-100.

[33]. Zeigler-Hill V, Pratt D. Defense. Defense Styles and the Interpersonal Circumflex: The Interpersonal Nature of Psychological Defense. Journal of Humanities and Social Sciences 2007; 1 (2):1-14. 
Relationship between Emotional Regulation Strategies and Self-reported Ego Defense Styles ..

[34]. Cramer, P., \& Tracy, A. The pathway from child personality to adult adjustment: The road is not straight. Journal of Research in Personality 2005, 39, $369-39$.

[35]. Luxen FM. Gender Differences in Dominance and Affiliation During a Demanding Interaction. The Journal of Psychology Interdisciplinary and Applied 2005, 139(4):331-47.

[36]. Marth C. Cultivating Humanity: A Classical Defense of Reform in Liberal Education. Cambridge, MA: Cambridge University Press, 1997. pp. 6-7. 